\title{
Interview with Julia Grinham, Commercial Director of Cogenz
}

\begin{abstract}
Julia Grinham
brings over ten years commercial experience in online publishing and information management to Cogenz. Julia started her career in sales and marketing at Reuters Plc (www.reuters.com), where her roles included launching the first web-based broker-research product into Asia, and managing two of Reuters' largest investment banking clients in London. In 2000 Julia joined the UK's leading local information site UpMyStreet (www.upmystreet.com) to head-up sales and business development, launching e-commerce and syndication business lines and growing advertising revenues. In 2003, she took on the role of Commercial Director to run UpMyStreet as a subsidiary of uSwitch (www.uswitch.com), re-launching the site, doubling the audience base and taking the business into profitability. Prior to joining Cogenz, Julia was Director of Consumer Markets at Hometrack Data Systems (http://www.hometrack.co.uk/), market leader in residential property information and valuations.
\end{abstract}

Keywords: social bookmarking, social media, taxonomy, metatag, silo, integration platform

Abstract Michael Moon interviews Julia Grinham, Commercial Director of Cogenz, a social bookmarking service for the enterprise.

Journal of Digital Asset Management (2007) 3, 306-316. doi:10.1057/palgrave.dam.3650107

MM: I'm here with Julia Grinham. Julia — just give me a quick background on Cogenz.

JG: Cogenz is a relatively small UK start-up company that was established in 2006. We launched a social bookmarking service for businesses in April.

Cogenz's main investors are venture capitalists Webface Technology Ventures, which incubates Web 2 startups. Cogenz is one of 5 companies that Webface have built up over the last few years, and it's probably the one that we've got the most hopes on, at this point in time.

The idea for Cogenz originally came from Niall Cook, who works for the PR firm Hill \& Knowlton. Webface's development team built the product through our development team in Sofia, Bulgaria.

We launched Cogenz as a beta service at the back end of 2006 with a small group of trial clients to help us develop and finalize the product itself. We then launched in April 2007.

My understanding of social media: tools that enable people to work together to create value in a collaborative way. So the whole suite of social media tools - which include blogs, wikis and RSS feeds provide a new way for people to share and consume information on the web, to create more value.

MM: How would you define the category of social bookmarking?
JG: Social bookmarking is a knowledge management tool. It's a way for people to save or bookmark, useful information they find on the web or on their corporate intranet; to easily search and retrieve that information; and to easily share that information with other people in their organization.

MM: How would it differ, say, from some of the existing social networking, bookmarking, sharing sites — like digg or del.icio.us?

JG: Cogenz is a very, very similar concept. We often call Cogenz "del.icio.us for the enterprise." It's about taking the functionality of social bookmarking services that are currently available in the public domain, and bringing them inside the organization's 4 walls.

That means instead of saving and sharing bookmarks with the world at large, you're only sharing your bookmarks with people in your organization. This is important in particular where you're researching things that are commercially sensitive - for example competitive intelligence. You don't really want to share that with the rest of the world. It's about making it private.

Cogenz also provides the organization with some control over how bookmarks or tags are structured. On the one hand, social bookmarking is about enabling employees make sense out of unstructured content and, what the 
organization has to do is let go and allow its employees to tag and categorize information as they want. However, what the organization can do with a closed system like Cogenz is actually shape and manage the way that data is categorized to help it make more sense for employees when they are searching for information.

MM:You have a super-administrator that would create a structure for it?

JG: Maybe a framework.

The classification with social bookmarking emerges from the bottom up, which is often called a "folksonomy." But the organization can combine the categorization that comes bottomup with any top-down corporate taxonomy system that they may already have in place. This blend of folksonomy with taxonomy provides a best-of-breed classification system.

MM: Or a hybrid.

JG: Or a hybrid. Rather than putting your resources into a library function and trying to determine how people should search, actually people want to be able to categorize and search for information in a way that makes sense for them.

MM: So in a sense, a way of speaking about that would entail web pages or objects found on the web being treated almost as autonomous objects. You are then collecting various objects - Web pages - and creating shared commentary on those objects as a way of providing some sort of insight in terms of a larger business objective or strategy. JG: Yes. I think for the individual it serves lots of functions. Firstly, if you're just looking at making your life more efficient, instead of saving your bookmarks in your desktop as people probably do now, you save them in a central environment so that you can find those bookmarks easily from wherever you are. You don't have to be by your computer. That makes life a little bit easier for you.

Secondly, if you find an interesting webpage, instead of having to e-mail it around to people you know, you just bookmark it, and it automatically gets shared with people in the organization. It helps you reach out to a much wider network of people rather than just e-mailing information to people you know.

There may be somebody in Singapore, for instance - or an office in Canada - who might find the information very, very useful. You don't know them, but by sharing it in a collective way, you can reach out to those people. Equally, you can get back information from them that they may be sharing with the organization.

In that respect, Cogenz starts to build up a picture of the knowledge networks that exist within the organization, where the pockets of knowledge are and who the experts are. That's really where the social networking comes into play. This is where it becomes very interesting.

From an enterprise management perspective, if you've got 1,000 people in the organization who are bookmarking on the desktop, you've got absolutely no idea what they're bookmarking. But if people are bookmarking in a shared collaborative environment, you can get a very good bird's eye view of the knowledge that's within the organization, and the connections that exist.

MM: This gets to - I think - a deeper issue, and I might say a controversy - in terms of the difference between information and knowledge. And in what produces information and knowledge.

One particular school of thought - I'll call them the "materialists," fundamentally believe that information exists separate from individuals or people. There's another group that basically calls that information wholly and completely human construct - assembled in the experience of individuals. There is no information in a system, per se. There are simply patterns that people make sense of. And for them, the primary process of making sense is some sort of social interaction and communication. What gives information value is its social context. JG:Yes. I think I would agree with that. Social bookmarking allows us to put our own meaning into information. But it's interesting, because not only do you see the meaning you place on that information, but also the meaning that others place on that same information. I think you then start to combine the two and make some collective decisions about what information means. MM: Right. This was getting to the point that in terms of social bookmarking, are we really managing objects, or are we managing interactions among people using the objects as a facilitator for the interaction? I would argue the latter. 
JG: I would argue the latter, as well.

MM: Really, it's an augmentation and enhancement of a conversation and interaction. A collaborative effort. This is simply a way of creating persistence in an otherwise highly fluid and sometimes geographically distended venue or requirement.

JG:Yes. I would agree with that.

MM: So what are some applications? Use cases?

JG: I can talk about three organizations that are using Cogenz quite extensively. One organization is called BUPA, the largest provider of private health insurance and healthcare services across the UK. BUPA is a knowledge-based organization and are trialling Cogenz across different parts of the business, as a way to harness some of this knowledge. Cogenz enables its users to easily search for and share information. It is particularly useful for project teams, whether they are in a central or disparate locations, looking for a convenient way to store and retrieve their research. At BUPA, Cogenz is being trialled across their brand and research functions. The social bookmarking tool allows the departments to store information on the public domain about the company and the health insurance industry. Sales and marketing teams may also find Cogenz useful to track information about customers, visitors and clients. In any parts of the business, where information and knowledge is crucial, Cogenz will prove invaluable. It's almost kind of easier to say, "Who wouldn't use it?"

MM: So in a marketing context, who is the primary driver or steward or custodian for the marketing? At least in terms of the top-down part?

JG: In terms of who would be responsible? MM: The taxonomy or the hierarchical structure that the bottom-up folksonomy would then kind of orient to?

JG: That's interesting. In our experience so far, Cogenz has been implemented solely as a folksonomy system. We haven't as yet worked with any clients who have integrated the social bookmarking folksonomy with a top-down corporate taxonomy system. That's the next stage for us. Some of the bigger clients we're talking to are trying to work out how they do that, with our help.
I would say that at the moment, Cognez is a very free tool that isn't being particularly controlled by any one person.

MM: In some of these larger clients that you're beginning to have these initial conversations with, what are some of the contours of those conversations?

JG: In terms of what their concerns and issues are?

MM: Concerns and issues, as well as a way of bringing some structure to the chaos of everyone just creating these shared bookmarks. Or do they care?

JG: I certainly think there's a bit of fear around how you control social bookmarking. I think there is a cultural shift that organizations have to make in understanding that you can't fully control folksonomy. That's the whole point of social bookmarking. The community itself should grow it.

But I think that clients are very interested in looking at how you build in or integrate folksonomy with taxonomy to come up with a better solution. The conversations are at quite early stages.

MM: Maybe another way of speaking about the folksonomy is it's almost a taxonomy of perception and desire, in terms of what out there has attracted my attention that I feel justified sharing it with other colleagues. Of all the things that people bookmark, the act of bookmarking constitutes a social act - that I want to share this with other people.

Then I've named it in a certain way so that other people with whom I want to share it with would recognize it as a particular conversation. Context and application, in each case.

If we stood back and said, "Let's look at that as an overall organizational phenomenon, as opposed to simply what I like and what I want to share," it really creates almost an abstract kind of four-dimensional view of how that organization relates to the world.

If you were to look at all the bookmarks and all the categories of bookmarks, each one of those represents a meaningful connection with something that's going on in the world.

You can think of that almost as a geodesic dome or a molecule or the surface of a fly's compound eye. You can see a lot of different facets. Each one of those facets represents a lens into the world - and more importantly a 
concern that we're trying to somehow better understand or get lined up behind.

JG: Are you saying that the social bookmarking gives an organization a view of how its people are thinking and how they view the world and how they basically think?

MM: How they're thinking collectively, actually.

JG: Yes.

MM: For example, in Cogenz's application, is there reporting that gives a senior-level manager or a senior administrator an overview, in terms of all the things that people have bookmarked by category?

JG: From a management perspective, you can look at what the recent items are that are being tagged. "What are the popular tags that people are categorizing that data against? Who are the most active users?"

That is the simplest level of analysis. We are looking at what other kind of tools clients want to run on top of this, to allow management to extract more value and understand the collective intelligence. We have an API, which basically allows an organization to do what they want with the data. So you can pull this data out and start to do some interesting analysis.

MM: Network analysis.

JG: Exactly. Using software that's out there.

MM: What's interesting about the phenomena of social bookmarking - again, from a more abstract perspective - was a way of [training] a new opportunity.

I see a parallel between this and prediction markers. Are you familiar with prediction markers?

JG: Not really.

MM: Prediction markers really are a very simple idea. You have a bunch of people making bets as to the probability of a certain thing happening at a point in time. Hence, a prediction.

So Google will buy this company by June of next year. People make bets. Just like betting on horses, it goes up or down — based on someone's confidence that that's going to happen.

It falls into a larger category of game theory. Specifically, it's the underlying game theory of stock markets. There, you have a whole bunch of different people with all different kinds of perspectives - and more specifically, local knowledge. Knowledge specific to them. Using some sort of mechanism by which to vote in a way that they don't influence other peoples' votes - thereby pre-empting groupthink.

There's some way of tallying or aggregating the net votes. For example, Google, Microsoft and Nokia use prediction markets to estimate when something will ship. And/or when a particular technology will be adopted by the mainstream. Then at Google, in fact, management uses prediction markets as a way of keeping track of 2000-3000 active research projects within Google, and when to commercialize them.

Again, it's another form of social network. And they create a game - like the stock market - by which to make guesses about when to do something, or when something is likely to happen.

JG: So you're saying that by collating the views of the community, the group then forms an opinion of what's going to happen in the future? MM: That's right.

JG: But not a self-fulfilling prophecy, where the group - because of the way and the things that actually then influence the prediction.

MM: That's correct.

Basically, you take some complex phenomenon that no one really has the totality of knowledge about what will happen. Basically, the outliers - the people that are very optimistic and the people that are very pessimistic tend to cancel each other out. The mean average tends to be pretty close.

It depends on a bunch of different factors, but some recent studies that I read about indicate that the Wisdom of Crowds ${ }^{1}$ tends to outperform expertise. Especially in areas of great complexity, like 9 times out of 10 .

JG: I imagine there could be some very interesting analysis of the data with Cogenz, to look at which of the tags emerge as being most popular, and watching the kind of timeline or volume of various information to see where it's going, particularly in terms of competitor analysis or market analysis. You could use this analysis to spot trends quite early on.

I think that would be a very interesting development. We don't have anything within the product itself right now to do that, but it would be very easy for an organization to develop the functionality to do that. That would be fascinating. 
We've already played around a little bit with some visual mapping of usage of Cogenz. For example, we've mapped the differing volumes of bookmarks that users produce; the proximity of users to each other from a social network perspective and visualizing that in a diagram which would depend on how many tags they are jointly tagging etc.

MM: This would be another tool - again, speculating - by which to reverse-engineer two particular kinds of social networks by which organizations get their work. One would be a network of expertise. Not necessarily a network of the most pleasant people. But these are the people that know stuff.

Then there's a network of support. These are the people that you to if you're confused about how to navigate a particular social organizational issue. Or how to do something. These are the people you go to for advice.

Usually the nodes of those particular networks are what we call [organization where the story is]. An organizational story has been there 10, 15, 20 years - and they tend to know, "Oh, well, that reminds me of the last time when we did an SAP R3 implementation, or when we did this blah-blah-blah," and here it's generally off. "You want to do that? Great. Then you've got to..."

So they kind of say, "Here's basically the pattern of our cultural norms." So bookmarking would tend to - again - reflect one or both of those networks. That might be a fascinating extension by which to start quantifying the value of these bookmarks.

JG: Yes.

MM: What else have you discovered among the users of your system?

JG: We think people are actually very prepared to share bookmarks. Whereas for some of the other social media tools such as wikis and blogs, there's quite a large cultural shift required to get true user adoption. Employees aren't used to collaborating. They're not used to writing documents together. Because who takes the credit for that? Who do they blame if something's wrong with the document?

Collaboration is quite a new way of thinking for some organizations and employees.

MM: We've also found in that dynamic, "Who's going to blame me?" And "Will I look bad?"
Those are some of the real inhibitors to collaboration.

JG: Whereas I think here, with social

bookmarking, there's not a huge change in user behavior required. Because pretty much everybody's used to bookmarking in some way, usually on their desktop. So it's not really a huge shift to bookmark in a central location. That makes it very, very easy to adopt.

With the companies we're working with now we find that 15 to $20 \%$ of people are posting, versus the rest of employees who are what we would call "browsers" of information.

MM: Tell me more about that.

JG: The percentage of people that are actually prepared to contribute information and put their bookmarks out there is about $20 \%$. I've from heard a lot of people here at Office 2.0 and also other people we talk to within the industry that usually the contribution levels to tools like blogs and wikis use are actually very, very small. I'm talking a $0.1 \%$ or a $0.5 \%$.

Social bookmarking has a much, much higher contribution level. I think again because it doesn't take a huge shift in user behavior.

MM: It's something that they're probably already doing. And the incremental effort to share it is probably low.

JG:Yes. I think you get something back instantly. For example, I subscribe to a daily alert from Cogenz, which tells me which new bookmarks people in my company have contributed. I got that from Day 1 of using the system. It was incredibly useful.

MM: Instant gratification. There you go.

JG: The more you use Cogenz, the more you get out of it. I like the fact that if I find something interesting on the web, I put it up on Cogenz as a bookmark. Other people in the organization kind of go, "Hey - Julia's finding out some interesting stuff. She's on the case. She knows what's going on."

I think people are quite prepared to share bookmarks. You're not giving away anything that's particularly personal, here. You're just saying, "Hey. I found something interesting. How about I share that with you?" It's not a huge deal (Figure 1).

MM: So bookmarking's a way of establishing some leadership on a particular area or front? JG: Yes. I think so.

MM: Without necessarily being boastful about it. 
JG:Yes. It's a kind of quite thoughtful thing. You're not giving away huge amounts of personal information. I think people feel quite comfortable with it.

MM: How do you deal with the issue that oftentimes I'll bookmark things and I'll go back a month later and go, "What was I thinking about here?"

JG:Yes.

MM: How do you deal with the transient memory loss? Or the failure to move it into long-term memory?

JG: In terms of retrieving something?

MM: Not of retrieving it. I bookmarked it.

JG: But now you want to bookmark it in a different way.

MM: No - why did I bookmark it? It's commenting about the bookmark.

JG:Yes. When you bookmark something, you have the opportunity not just to tag it, but also to add a comment or note. So if you're using your brain, you probably put something in here about what this information is about. And why it was useful to you.
The more information you put in, the more useful it's going to be to you and others later, to find it.

MM: So this is your edit/bookmark form.

JG:Yes. And this is the same form as if you're initially posting a bookmark.

MM: Could I extend this form by adding some checkboxes or pull-down menus to augment the structure?

JG: Yes. Absolutely. With this kind of out-of-thebox solution, no. But with the Cogenz API, a company can take this form and make it into whatever they want.

MM: Like a rating system.

JG:Yes. You could put a rating system into it. You could have a dropdown menu with your corporate taxonomy. So people could tick the things that you use in your corporate taxonomy system. Plus they could put their own free-form tags in.

MM: Sure.

JG: So you can kind of shape it how you want to. That's quite interesting.

You can also post things simultaneously to del.icio.us, as well as posting to your

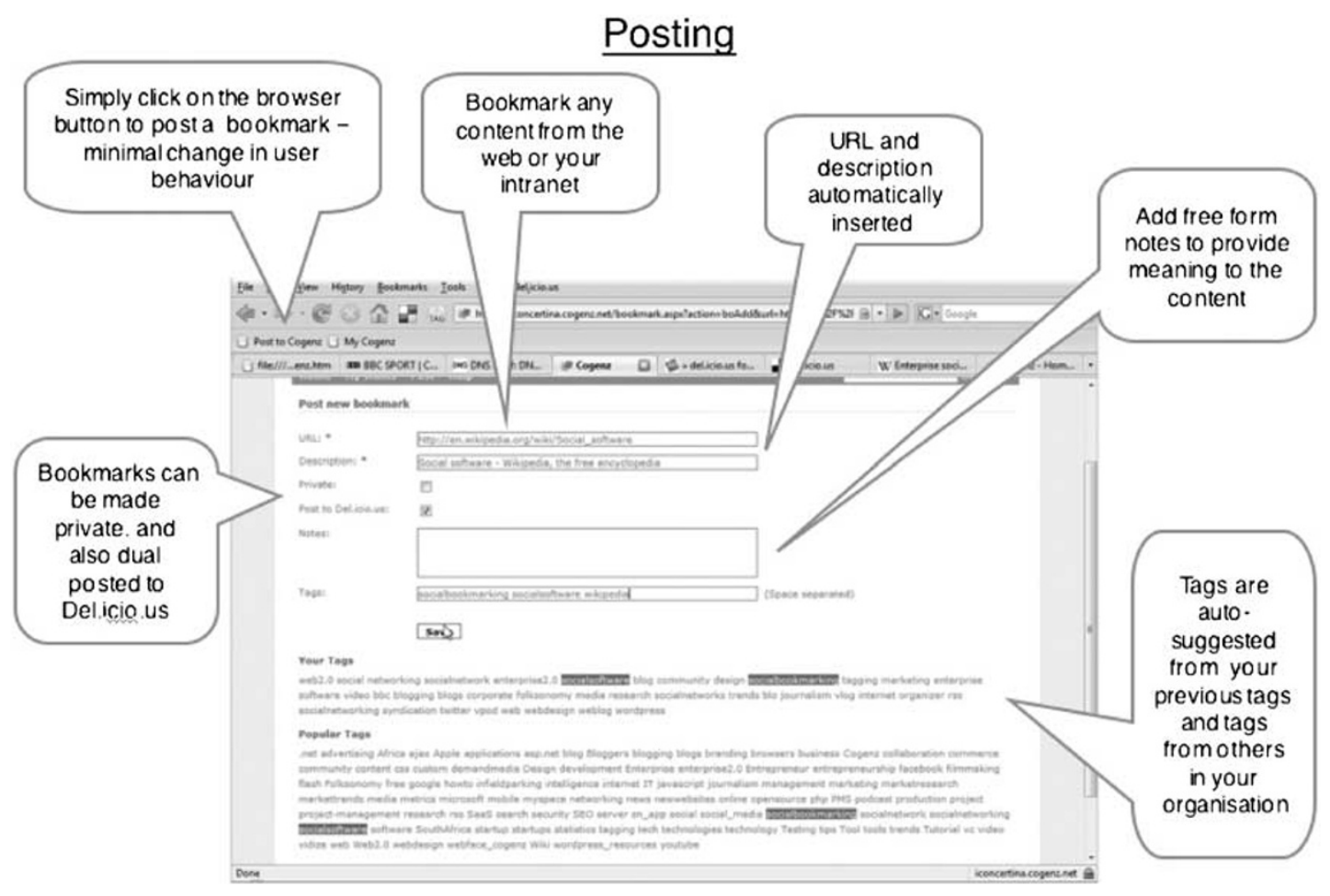

Figure 1: Posting bookmarks to Cogenz 
corporate system. I think for the knowledge worker, particularly in a lot of industries with a lot of movement of people between organizations, you want to take your knowledge with you.

I think that's another thing that makes this attractive to people. I'm not just giving all my knowledge to the company here. I'm also kind of keeping it for my own use. I can take that wherever I want.

MM: For example, let's say I was working on a project with a couple of clients. I want to create a sandbox for a protected area, public facing as opposed to...

JG: As opposed to something you share with your clients.

MM:Yes. Is that easily done?

JG: Yes. You just get set up as a user.

MM: So then you can partition certain areas?

JG:You can. That's all done within the superadministration. We recognize there are a lot of organizations where there are Chinese walls where information cannot go between them. So you can set up divisions within it.

The more you use the system, the more you build up your own database of tags.

The popular tags are tags that other people have used. When you go to tag something, it will also suggest what might be appropriate. If I were bookmarking something about social bookmarking, you can see that already it comes up with some suggested tags.

MM: And you can have multiple tags, then.

JG: Absolutely. Yes. You can have as many tags as you like. You can see that it can start off by seeming quite unstructured and perhaps a bit messy. But actually over time, what happens is that order starts to form out of the chaos.

MM: This is what I was getting to when I was talking about the taxonomy of perception. You could almost call it the taxonomy of concern.

JG: Yes. You have to give it some time. The longer it goes on, the more structured it becomes.

MM: Are there any things you've seen among your early adopters to accelerate or speed the emergence of that?

JG: I think to start with, it's useful to start by populating the system with some content. You don't put this in front of 10 users as an empty box and kind of go, "Off you go." They're going to come to it and go, "Hey. What is this thing?"

MM: What's the idea? Is there a critical mass number in terms of either postings or tags or categories that you've observed?

JG: That's an interesting question. I don't know the answer to that, actually. I think it's probably too early for us to say.

MM: If you were to take what they call a SWAG?

JG: I think as long as you kind of come into it and you see three or four users - you see perhaps ten tags - and you see at least 1 page worth of bookmarks - you're kind of probably going to "get it." I think that's enough to get someone started.

MM: The point I'm trying to get to here is that essentially adoption is a game. It incorporates all that we know about game theory and what makes games fun and engaging. A little bit of a challenge. Personal identification. Immediate gratification. A way of keeping score.

So at what point in an organization does it go from an items of interest to an item of, "I've got to play it?" What are some of the facets that you've seen that are part of that? Surely, some of them would be the topics. Some of them would be the "Who's playing it?"

JG: Oh, yes. I mean if your boss is in there, you kind of think, "I should be reading what my boss is bookmarking." If I can do that, that's probably one very good reason for looking at this. I can get insight into what he's thinking. MM: Or it could be if someone took the initiative and bookmarked all of the competitors as a way of doing your informal benchmarking. You could almost call it "content benchmarking."

JG: I think it would depend from organization to organization. If you're a team of 5 people and you all sit next to each other, it's going to be less valuable than a team of [500] who sit in 5 different locations. Instantly, you've got a new communication tool. I do think it depends. I think it's too early for us to say.

I don't feel we have enough real examples to try to generalize about what those things are. MM: Do you have any examples you could tell me about?

JG: We do. One of the companies within the Webface group is called iConcertina. They're a web-design agency. We also have another client 
called HeadShift. I don't know if you've heard of them. They're quite well known certainly in the UK. They build Enterprise 2.0 applications for businesses, and have about 30 staff.

All of their users are using it. They all sit in the same office, but they're all using it.

MM: That would make sense, because they're already web-savvy to begin with.

JG: Yes. They get it.

MM: This introduces an interesting distinction - especially for people that are older than I.

I have both a cognitive science background and... Let's just deal with that. I have a cognitive science background. I've made a particular effort to understand how it is people experience what they experience. Not just what they think, but how they feel, how they sense - how they actually experience what they experience.

I try to understand that in a systematic structured way.

In the course of studying that particular area of cognitive science, it's given me a particular insight into everyone kind of experiences the world in a really different way. And

generationally from one generational corridor to another, there are oftentimes some really radical ways by which people experience the world.

For example, for people that are 30 years or younger, they grew up already wired. They not only came cable-ready... they came net-ready. Right?

So from their first and earliest experiences of the web, it was probably IMing their friends and/or SMSing their friends. You and I will have 2 hands. They don't have 2 hands.

JG: They have 2 fingers.

MM: No, they actually have a third hand. A third digital hand. This digital third hand is quite literally their fluidity in terms of all things digital. They just already assume. They don't "come" to the web. The web kind of lives in them as an ongoing cognitive process.

So they're never offline, as an experience. They tend to adopt these Web 2.0 things as just a matter of, "Well, gee - that's an interesting sweater. I think I'll try that on," as opposed to coming at it as a foreign object that I've got to negotiate with.

I imagine there'd be some interesting adoption patterns for things like social bookmarking for those that are third-handers or not.
JG: I'd like to spend some more time with BUPA, actually, on that. I imagine that they've got quite a broad range of people from different generations who'd have a different experience.

MM: It would seem to me that that would be the area that I would strategically mark as my market-making segment. I would say, "Look. I don't have time. I don't have energy. I don't have the money to educate flat-worlders or old-style 2-handers in the value need necessity and fluidity of having a third hand. So let's start with the third-handers, and see how they will take this."

They don't know what it is not to be connected. For them, it's beyond. Not to offend an old client of mine - Nokia connecting people. That's so "yesterday."

It's like, "What do you mean? I've never known not being connected."

What is a meaningful brand and/or a meaningful product in that context?

JG: I think it'd be very interesting to find that. I think anybody who's at work is probably bookmarking stuff on their desktops. I don't know. I could be wrong about that. But I just kind of assume that. That's why I think it's not a huge leap of faith to actually bookmark.

I think it's probably more of a job to get people to go into the system and understand how they can get stuff out of it. I think that organizations - to make it really fly - needs to integrate social bookmarking including the search and retrieval element of is, into existing systems and processes (Figure 2).

You don't want Cogenz to be yet another tool that you've got to go into to get the information. You want to publish it on the intranet.

MM: This reminds me... Again, I'm revealing a little bit of my age. When spreadsheets were brand new. I met the founders of Visacal or Personal Software, as it was, then - and the guys that started Lotus 123. I remember the Herculean effort that it entailed, from getting mid-level accounting managers to assimilate and inculcate the commands of Visacal for Lotus 123.

In fact, I remember distinctly that people created all kinds of cheat sheets and posters as a way of reminding them, "Oh, yes. Control-this or Command-that." Or whatever. 


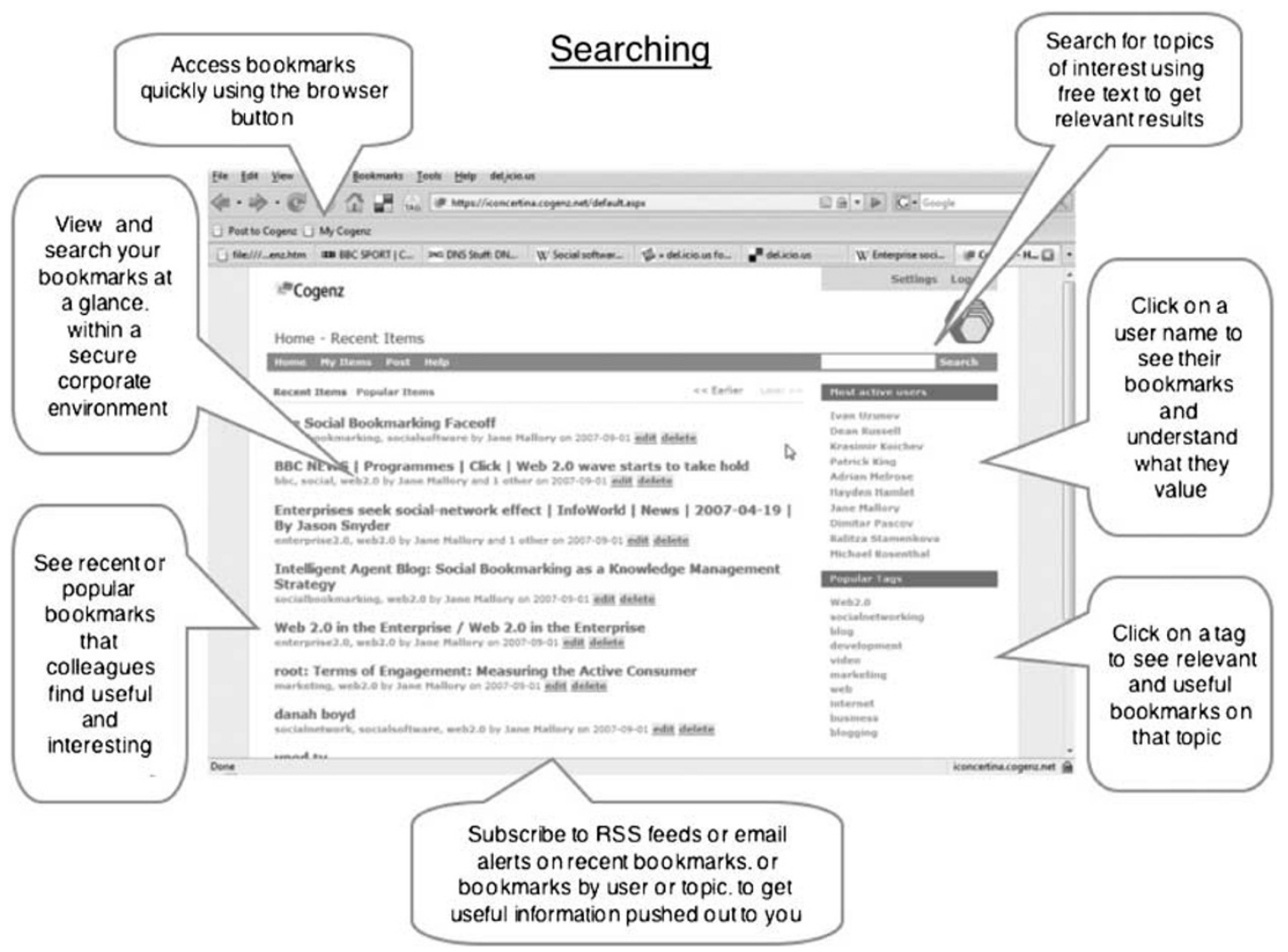

Figure 2: Searching on Cogenz

So it might be that there's a similar requirement around this. Almost a cheat-sheet or a quick-start or a fast track or a bookmark.

JG: I think from what BUPA told me, because I asked them about how they rolled it out to people and how they educated. They said they didn't really need to do a huge amount of education. It was a very brief kind of thing. "This is what bookmarking is. This is how you do it. This is what you'll get out of it."

So there actually was an easy rollout. But they got management support. I think that it is quite important to have that top-down support. But BUPA said it wasn't that difficult. It's encouraging.

MM: I would think, though, that every month you'd put out a new cheat-sheet of, "Here's collectively what we want to bookmark. So in your normal course of events, here's what we want to bookmark collectively, and here are the terms that we've already kind of set up for the automatic tagging. Here are the terms we'd like you to use.
Use whatever else you want, but here are some of them." Kind of like a starter kit.

But making it a game. Once a week - once a month - a new game.

JG: Yes. That would be one way of doing it. MM: As a way of accelerating. There's clearly critical mass. Correct?

JG: Yes. But I don't know where that critical mass is. I think it depends on the size of the organization.

MM: Yes. We might just still be too new.

JG: We'll see. I think we've got a helluva lot to learn about what this actually means for people. MM: Anything else I should know about Cogenz at this point?

JG: At the moment Cogenz is a hosted solution. But we've been talking to lots of clients in the market, and we recognize that a lot of them want to put Cognez behind their firewall.

MM: Sure.

JG: We are launching as a server version in the next quarter. That's kind of interesting. I think 
it's almost a shame, really, that some companies aren't ready for a hosted solution, yet. It's such a low-cost, easy-to-implement way of doing things - by using software as a service. But the market isn't ready for it, yet. So we're having to address that.

MM: We've actually been tracking this now for quite some time. This software. This service. We're actually now in the second wave of software as a service, where integration platforms are now playing a pivotal role. We're about to enter this 3rd one, which this whole conference has been about. That is not software as a service - not software integration platforms as a service - but functions as a service.

So where you take an application and you say, "Hey. Here's a set of widgets".

JG:You kind of pick-and-build.

MM:You match it up and say, "Hey. That's what we're using."

JG:Yes.

MM: That basically throws the whole conceptual part of work of, "What are we trying to do and how are we going to do it and how do we integrate all of that," back on the user. JG: Back on the user. Yes.

MM: More specifically, the individual that's least prepared to noodle through that kind of stuff.

So we're in for - I imagine, sometimes some very creative and innovative breakouts for the public. For many. For a whole lot of people. For a huge [market].

JG: We just launched our API officially today with a press release. We've also put in place a competition for developers to build applications off the back of our API. We'll put our hands up and say that we are not the experts in how we could the Cogenz API could be used to create different applications within an organization. So we want to push it back out to the development community and say, "This is what social bookmarking is for the enterprise, but you decide how would you actually use it and integrate it, and what could you build from it?"

I think it's going to be very interesting to see what comes out of that.

MM: Have you done or do you provide a sandbox? Obviously you published your APIs. But do you provide a sandbox, which would be a version of the system for developers to integrate to and mess up?
JG: I don't know, actually. I don't know the answer to that.

MM: That'd be a really good thing.

JG:Yes. That's going to be quite interesting to see what comes out of it. But yes, we're quite excited and pleased by the response we've had here at Office 2.0. Social bookmarking has not been hugely written about, yet it's one of the newer tools that are coming into the enterprise. Blogs have been around for a while. Wikis have been around for a while. But social bookmarking is still relatively new — with still only a handful of players.

I think it's going to be a very interesting six to twelve months - to see how it shapes up. Did you see Connect Beam? They play in a similar space as us.

MM: How would you differentiate Connect Beam and Cogenz?

JG: The main difference is that Cogenz focuses purely on social bookmarking. Whereas Connect Beam also bring in an element of an employee directory (kind of like Linked-In) aspect; user profiles.

I'm not really sure how that works when a company already has an existing corporate directory with user profiles. Indeed, with the Cogenz API it is very easy to integrate the system into an existing corporate directory, so why buy in this additional functionality?

MM: It would seem to me that that linked in framework would work well where you're really talking about a skills inventory. Where you have the official profile and you have the "Who are you," in terms of a network of expertise or a network of support.

For example, whom do we know in Turkmenistan? Or whom do we know in Azerbaijan?

JG: That kind of broader [thing]. They're also more expensive than Cogenz. And they're focusing on a slightly bigger kind of corporate type sale. We're kind of low-cost, simple-toimplement solutions for mainly a medium-sized enterprise.

MM: What's the pricing on this?

JG: It's free for up to ten users. That's great. Because you can just kick it about and see what it's like. Then depending on the number of users, it's between $\$ 2$ and 4 per user per month. So it's fairly low-cost. 
It's not that it's an insignificant decision. I think you can't say, "Oh, it's easy. Its kind of Web 2.0 and it's easy." But companies do need to think about how they're going to integrate it and how they're going to roll it out. How they're going to encourage users to use it. At least the monetary side of it isn't or shouldn't be a barrier for companies.

MM: Other than Connect Beam, whom else? JG:You've got the big enterprise players like IBM and BEA Systems.

MM:Yes.

JG: These organizations provide suite of Enterprise 2.0 tools, which include a social bookmarking element.

So it'll be interesting. There've been lots of debate here at Office 2.0 about whether enterprises will take best-of-breed applications from niche players like Cogenz and integrate them themselves or whether they'll go through the established vendors such as IBM and take the suite. There'll obviously be a bit of both, and we'll see where it goes.

But Cogenz is looking at ways we can partner with other organizations - whether they're technology companies or distribution partners - to take our product to market in the way that best meets what the customer is looking for.

MM: It seems to me that social bookmarking needs a really compelling and cogent value proposition. One that I have not yet heard articulated.

I believe from my opening remarks that the compelling value proposition will reflect the social interaction that shared bookmarks facilitate - as opposed to their being value in the information.
JG:Yes.

MM: This gets to another of my rants. That is that we have too much information. The knowledge worker today has way more information than he or she could ever use. What we lack is context. What does this mean? What does it importantly? What action can I take?

The fastest and most direct way of creating context among adults, anyway, entails conversation, interaction and collaboration.

The game for context making — that's the scarce resource - is, "What can we do to facilitate communication and interaction and collaboration?" It seems to me that if we then bring in adult learning theory, that basically says, "Well, it's got to be non-hierarchical from here to here. Something fun to play and nobody's keeping score.

Those seem to make my overall framework for what it's going to take for social bookmarking to become really mainstream. The value proposition is linked to a deeper, more meaningful and richer context, by which to inspire or align energy [and action].

JG: We can't wait to see what's going to come out of this, as we get more and more case studies. I think we're going to see some very, very interesting analysis and patterns developing. MM: I want to thank you very much.

\section{Reference}

1 Surowiecki, J (2004) The Wisdom of Crowds: Why the Many Are Smarter Than the Few and How Collective Wisdom Shapes Business, Economies, Societies and Nations. Little, Brown (ISBN 0-316-86173-1). 